\title{
Airway resistance at maximum inhalation as a marker of asthma and airway hyperresponsiveness
}

\author{
Nancy T Mendonça', Jennifer Kenyon'1, Adam S LaPrad', Sohera N Syeda², George T O'Connor ${ }^{2}$ and \\ Kenneth R Lutchen ${ }^{1 *}$
}

\begin{abstract}
Background: Asthmatics exhibit reduced airway dilation at maximal inspiration, likely due to structural differences in airway walls and/or functional differences in airway smooth muscle, factors that may also increase airway responsiveness to bronchoconstricting stimuli. The goal of this study was to test the hypothesis that the minimal airway resistance achievable during a maximal inspiration $\left(R_{\min }\right)$ is abnormally elevated in subjects with airway hyperresponsiveness.
\end{abstract}

Methods: The $\mathrm{R}_{\min }$ was measured in 34 nonasthmatic and 35 asthmatic subjects using forced oscillations at $8 \mathrm{~Hz}$. $R_{\min }$ and spirometric indices were measured before and after bronchodilation (albuterol) and bronchoconstriction (methacholine). A preliminary study of 84 healthy subjects first established height dependence of baseline $R_{\text {min }}$ values.

Results: Asthmatics had a higher baseline $R_{\min } \%$ predicted than nonasthmatic subjects (134 \pm 33 vs. $109 \pm 19 \%$ predicted, $p=0.0004$ ). Sensitivity-specificity analysis using receiver operating characteristic curves indicated that baseline $R_{\min }$ was able to identify subjects with airway hyperresponsiveness $\left(\mathrm{PC}_{20}<16 \mathrm{mg} / \mathrm{mL}\right.$ ) better than most spirometric indices (Area under curve $=0.85,0.78$, and 0.87 for $\mathrm{R}_{\min } \%$ predicted, $\mathrm{FEV}_{1} \%$ predicted, and $\mathrm{FEF}_{25-75} \%$ predicted, respectively). Also, $80 \%$ of the subjects with baseline $R_{\min }<100 \%$ predicted did not have airway hyperresponsiveness while $100 \%$ of subjects with $R_{\min }>145 \%$ predicted had hyperresponsive airways, regardless of clinical classification as asthmatic or nonasthmatic.

Conclusions: These findings suggest that baseline $R_{\min }$, a measurement that is easier to perform than spirometry, performs as well as or better than standard spirometric indices in distinguishing subjects with airway hyperresponsiveness from those without hyperresponsive airways. The relationship of baseline $R_{\min }$ to asthma and airway hyperresponsiveness likely reflects a causal relation between conditions that stiffen airway walls and hyperresponsiveness. In conjunction with symptom history, $R_{\min }$ could provide a clinically useful tool for assessing asthma and monitoring response to treatment.

\section{Background}

Structural alterations in asthma include inflammation, increased airway smooth muscle mass, and increased airway wall thickening [1]. These are not easily assessed in patients, so clinicians rely on functional measurements such as spirometry and tests of airway hyperresponsiveness to assess the presence and control of asthma. Another

\footnotetext{
* Correspondence: klutch@bu.edu

'Department of Biomedical Engineering, 44 Cummington St., Boston University, Boston, MA 02215, USA

Full list of author information is available at the end of the article
}

characteristic of asthma is higher airway resistance at maximal inspiration compared to nonasthmatics. Jensen and co-workers [2] used the minimum resistance achieved at maximum inspiration (Rmin) as representing the maximum airway dilation achievable (averaged over the entire lung) by a subject. They showed that Rmin was abnormally high (i.e., less ability to dilate the airway tree) in asthmatic versus nonasthmatic subjects [2]. Salome and co-workers confirmed the reduced ability of asthmatics to dilate after deep inspiration and also showed that the magnitude of dilation was negatively correlated

\section{Ciomed Central}


with re-narrowing in nonasthmatics [3]. Black and coworkers [4] showed that respiratory system resistance $\left(\mathrm{R}_{\mathrm{rs}}\right)$ measured noninvasively by forced oscillation at maximal inspiration represented the same Rmin as in the Jensen study because the chest wall does not contribute to $R_{r s}$ at maximum inspiration. These studies attributed the reduced dilation seen in asthmatics at maximum inspiration to increased stiffness of airway smooth muscle (ASM), reflecting structural characteristics such as hypertrophy and a more contractile state of ASM that may be associated with airway hyperresponsiveness, which is a defining characteristic of asthma.

The goal of this study was to test the hypothesis that the minimal airway resistance achievable during a maximal inspiration $\left(R_{\min }\right)$ is abnormally elevated in subjects with airway hyperresponsiveness. To test this hypothesis, we measured $R_{r s}$ in nonasthmatic and asthmatic adults during tidal breathing and at maximal inspiration at baseline, following albuterol-induced bronchodilation, and following methacholine-induced bronchoconstriction. Because airway resistance is related to height, we examined the relationship of $R_{\min }$ to height in nonasthmatic volunteers so that $R_{\min }$ could be analyzed as a percent of the predicted value. In addition, we compared $R_{\min }$ to spirometric indices in terms of their relationship to methacholine airway responsiveness. If $R_{\min }$ measured by forced oscillation accurately reflects airway hyperresponsiveness and structural abnormalities associated with airflow limitation, it may provide a valuable clinical test to help assess the presence and control of asthma that is easier to perform than spirometry.

\section{Methods \\ Subjects}

Participants were recruited by advertisement. Asthmatic participants $(\mathrm{n}=35)$ had a clinical diagnosis of asthma and were taking inhaled bronchodilator. Nonasthmatic subjects $(\mathrm{n}=34)$ denied any history of respiratory symptoms or diagnoses. Participants in both groups were required to have less than 10 pack-years of tobacco smoking. In a substudy to determine the height dependence of resistance measurements, we recruited 84 additional nonasthmatic participants who denied smoking, occupational exposure to smoke or dust, respiratory symptoms, and any respiratory disease history. All subjects provided informed consent, and this research was conducted in compliance with the Helsinki Declaration. This study was approved by Boston University Medical Center IRB, Protocol H-25546, and Boston University Charles River Campus IRB, File 1765E.

\section{Experimental Protocol}

Asthmatic subjects withheld short-and long-acting bronchodilators 6 and 24 hours, respectively, prior to study visits. All subjects attended two test days at least 24 hours apart. On day 1 , the forced oscillation system described below was used to measure end-inspiratory $R_{r s}$ during tidal breathing and $R_{\min }$ at maximum inspiration. Subjects took six tidal breaths followed by a slow maximum inspiration followed by a passive exhalation and six more tidal breaths. The procedure was repeated. Subjects then performed spirometry. After baseline studies, subjects inhaled two inhalations of albuterol metered-dose inhaler $90 \mu \mathrm{g} /$ inhalation via spacer. Forced oscillation and spirometry measurements were repeated after 10 minutes.

On day 2 , baseline measurements of $R_{\min }$ and spirometry were obtained, followed by methacholine challenge. Methacholine (Provocholine ${ }^{\circledR}$, Methapharm, Canada) was administered in the following concentrations: $0.098,0.195,0.391,0.781,1.563,3.215,6.25,12.5$, and $25 \mathrm{mg} / \mathrm{ml}$. Other than this concentration schedule, testing was performed in accordance with current ATS recommendations using the 5-breath dosimeter protocol [5] using equipment described below. At the conclusion of the challenge (i.e. when a $20 \%$ decline in FEV1 occurred or after the final dose of $25 \mathrm{mg} / \mathrm{ml}$, whichever came first), $R_{\min }$ was measured again, and then 2 inhalations of albuterol were administered. Spirometry and $R_{\text {min }}$ measurements were repeated 10 minutes after albuterol administration.

In the sample of nonasthmatics studied to establish the relationship of $R_{\min }$ to height, only $R_{\min }$ and height were measured.

\section{Measurement of $\mathbf{R}_{\mathbf{r s}}$}

We measured $R_{r s}$ as previously described [4]. Briefly, a 12-in diameter subwoofer delivers an $8 \mathrm{~Hz}$ oscillation, with amplitude of $\pm 1 \mathrm{cmH}_{2} 0$, superimposed on spontaneous breathing. Jensen and co-workers [2] showed that because soft-tissue is viscoelastic, it has a tissue resistance that decreases hyperbolically with frequency and that by $8 \mathrm{~Hz}$ the lung tissue resistance is negligible and the chest-wall tissue resistance is at its minimum. A three-way valve allows the subject to breathe fresh air through a high-inertance tube. Flow at the airway opening is measured by a pneumotachograph (4700 Series, Hans Rudolph, Kansas City, MO) connected to a differential pressure transducer (ATD02AS, SCIREQ, Montreal, QC). Pressure at the airway opening is recorded with a differential pressure transducer (ATD5050, SCIREQ). These pressure and flow signals are transmitted through demodulator circuits and then to a 10 Hz low-pass filter (S/N 980987, SCIREQ). The filtered signals are sampled at $40 \mathrm{~Hz}$ and stored digitally by LabView (National Instruments, Austin, TX). Pressure and flow data were separately low- and high-passed filtered using Matlab software (Natick, MA) at a cut-off 
frequency of $4 \mathrm{~Hz}$. The signals were processed using a recursive least squares algorithm, described previously [2], to estimate $R_{r s}$ eight times per second. Minimum airway resistance, $R_{\min }$, was derived as $R_{r s}$ at maximum inspiration.

The system used in the substudy of nonasthmatic subjects $(n=84)$ conducted to determine normative predicted values for $R_{\min }$ differed only in its differential pressure transducers (Model LCRV, CELESCO, Chatsworth, CA) and had a 1\% error from the system used in the main study.

\section{Spirometry and methacholine challenge methods}

Spirometry measurements were made with an integrated spirometer-dosimeter system (KoKoDigidoser ${ }^{(B)}$ spirometer, Ferraris Respiratory, Louisville, CO) using the DeVilbiss 646 nebulizer. Our measured nebulizer output was $8.7 \pm 0.8 \mathrm{uL} /$ breath (mean $\pm \mathrm{SE}$ ), very close to that reported in the literature for this equipment[6]. Predicted values for spirometric indices were based on published regression equations [7]. Spirometry was performed in accordance with published standards [8]. For methacholine challenges, interpolation was used to calculate the provocative concentration causing a $20 \%$ drop in $\mathrm{FEV}_{1}\left(\mathrm{PC}_{20}\right)$. We also calculated the methacholine dose-response slope [9] as a two-point slope of a line connecting the first and last point of the doseresponse curve, measured in units of \% decline from baseline $\mathrm{FEV}_{1}$ per $\mathrm{mg} / \mathrm{mL}$ of methacholine, an approach that permits analysis of methacholine responsiveness as a continuous measure even in subjects not experiencing a 20\% decline in $\mathrm{FEV}_{1}$. For logarithmic transformation of dose-response slope prior to graphic display and correlation analysis, the constant 0.1 was first added to deal with zero or slightly negative values.

\section{Data Analysis}

Among subjects that denied asthma, those with a $\mathrm{PC}_{20}$ greater than $25 \mathrm{mg} / \mathrm{mL}$ were defined as "nonasthmatic methacholine nonresponders." Among subjects that reported asthma, those with a $\mathrm{PC}_{20} \leq 25 \mathrm{mg} / \mathrm{mL}$ were defined as "asthmatic methacholine responders."

A second-order linear regression analysis, using the bisquare method[10] to account for undue influence of outliers, was performed to derive a prediction equation for $R_{\min }$ based on height, using data from 84 nonasthmatic substudy participants and 26 of the 34 nonasthmatic participants in the full study who had a $\mathrm{PC}_{20} \geq 25$ $\mathrm{mg} / \mathrm{ml}$. Predicted values calculated with this equation were used to derive $R_{\min } \%$ predicted $=\left(\right.$ measured $R_{\text {min }}$ (predicted $\left.\mathrm{R}_{\min }\right) * 100$.

Statistical comparisons were made using paired or unpaired t-tests, or a Mann-Whitney Rank Sum test if a test of normality or equal variance failed, with a significance level of 0.05 . Correlations were examined using the Pearson correlation coefficient. For subjects that did not experience a $20 \%$ or greater decline in FEV1 by the highest concentration of $25 \mathrm{mg} / \mathrm{mL}$, we assigned a $\mathrm{PC}_{20}$ value of $25 \mathrm{mg} / \mathrm{mL}$ so that we could calculate a geometric mean for Table 1 (Subject characteristics).

Receiver operator characteristic (ROC) curves to examine the ability of Rmin \% predicted and other parameters to predict airway hyperresponsiveness (defined as a $\mathrm{PC}_{20}<16 \mathrm{mg} / \mathrm{mL}$ ) were created by plotting sensitivity (true positive rate) versus 1-specificity (true negative rate), for each value of the test. The best threshold for any test is that which maximizes sensitivity while minimizing the false positive rate, represented by the left upper most value on the curve. The area under the curve (AUC) represents a measure of test accuracy (AUC of 1.0 indicates perfect prediction; AUC of 0.50 indicates prediction no better than chance) and was calculated via numerical integration.

\section{Results}

\section{Subject Characteristics}

We studied 34 nonasthmatic and 35 asthmatic participants with similar demographic and anthropomorphic characteristics (Table 1). Only two of these subjects (both nonasthmatics) were current tobacco smokers. Asthmatics had lower spirometric indices and greater methacholine responsiveness than nonasthmatics. Among the 34 nonasthmatic subjects, 26 were classified as "nonasthmatic methacholine nonresponders" as defined above. Among the 35 subjects that reported asthma, 31 subjects were classified as "asthmatic methacholine responders" as defined above. The 84 additional

Table 1 Characteristics* of 34 nonasthmatic and 35 asthmatic participants

\begin{tabular}{lcc}
\hline & $\begin{array}{c}\text { Nonasthmatic } \\
(\mathbf{n}=\mathbf{3 4})\end{array}$ & $\begin{array}{c}\text { Asthmatic } \\
(\mathbf{n}=\mathbf{3 5})\end{array}$ \\
\hline Sex & $22 \mathrm{~F} / 12 \mathrm{M}$ & $22 \mathrm{~F} / 13 \mathrm{M}$ \\
Age (yr) & $21 \pm 2$ & $21 \pm 3$ \\
Height (cm) & $170 \pm 10$ & $168 \pm 10$ \\
Weight (kg) & $65 \pm 13$ & $66 \pm 12$ \\
FEV1 (\% predicted) & $95 \pm 10^{\dagger}$ & $88 \pm 11$ \\
FEV1/FVC (\% predicted) & $100 \pm 7^{\dagger}$ & $90 \pm 9$ \\
PC20 (mg/ml) & $19 \pm 2^{\dagger}$ & $1.8 \pm 5.2$ \\
& median: 25 & median: 1.3 \\
$\geq 25$ & 26 & 4 \\
$16-24.9$ & 1 & 0 \\
$8-15.9$ & 4 & 5 \\
$<8$ & 3 & 26 \\
\hline
\end{tabular}

* Mean \pm standard deviation is shown for continuous variables, except for $\mathrm{PC} 20$, which is geometric mean \pm standard deviation.

$+\mathrm{p}<0.05$ 
nonasthmatic subjects, who underwent only forced oscillation and anthropomorphic measurements, had a mean age of 21 and were $55 \%$ males.

\section{Dynamic Rrs tracings and determination of $R_{\min }$ in representative subjects}

Typical tracings of $R_{r s}$ and relative volume for a nonasthmatic and an asthmatic subject are shown in Figure 1. For the asthmatic participant shown, the mean end-inspiratory pre-deep inspiration $R_{r s}$ was 2.36 $\mathrm{cmH}_{2} \mathrm{O} / \mathrm{L} / \mathrm{s}$, and $\mathrm{R}_{\min }$ was $1.46 \mathrm{cmH}_{2} \mathrm{O} / \mathrm{L} / \mathrm{s}$, values approximately $50 \%$ higher than those of the nonasthmatic subject shown $\left(1.45\right.$ and $0.99 \mathrm{cmH}_{2} 0 / \mathrm{L} / \mathrm{s}$ for $\mathrm{R}_{\mathrm{rs}}$ and $R_{\min }$, respectively).

\section{Relationship Between $\mathbf{R}_{\min }$ and Height}

We examined the relationship between $R_{\min }$ and height among the 84 subjects that underwent limited testing plus the 26 nonasthmatic methacholine nonresponders in the full study. These two groups displayed a similar relationship between $R_{\min }$ and height (Figure 2) and were therefore analyzed together. Regression analysis of these 100 subjects revealed the following relationship:

$$
\mathrm{R}_{\min }=7.20-5.46 * \text { Height }+1.07 * \text { Height }^{2} .
$$

The $\mathrm{R}^{2}$ for this model (regression line superimposed on Figure 2) was 0.60, indicating a relationship between $R_{\text {min }}$ and height of similar strength to that between spirometric measurements and height [7]. $R_{\min }$ was not significantly related to sex or body-mass index after accounting for height.

\section{$\mathbf{R}_{\min } \%$ predicted as an indicator of asthma and airway hyperresponsiveness}

The baseline $R_{r s}$ (end-inspiration values averaged over 6 pre-deep inspiration tidal breaths), $\mathrm{R}_{\min }$, and $\mathrm{R}_{\min } \%$ predicted differed significantly between asthmatics and nonasthmatics, as did spirometric indices (Table 2). These differences were even more pronounced when comparing nonasthmatic methacholine nonresponders and asthmatic methacholine responders (Table 2). The $\mathrm{R}_{\min } \%$ predicted was significantly greater among asthmatics than nonasthmatics in all conditions (baseline, post-albuterol, post-methacholine), differences that were even more pronounced when comparing asthmatics to nonasthmatic methacholine nonresponders (Figure 3). Among subjects without asthma, the $R_{\min }$ was greater among those with a $\mathrm{PC}_{20} \leq 25 \mathrm{mg} / \mathrm{mL}$ than among those with a $\mathrm{PC}_{20}>25 \mathrm{mg} / \mathrm{mL}\left(\mathrm{R}_{\min } \%\right.$ predicted $131.7+/$ 5.3 SE vs. $102.1+/-2.9$ SE, $\mathrm{P}<0.0001)$.
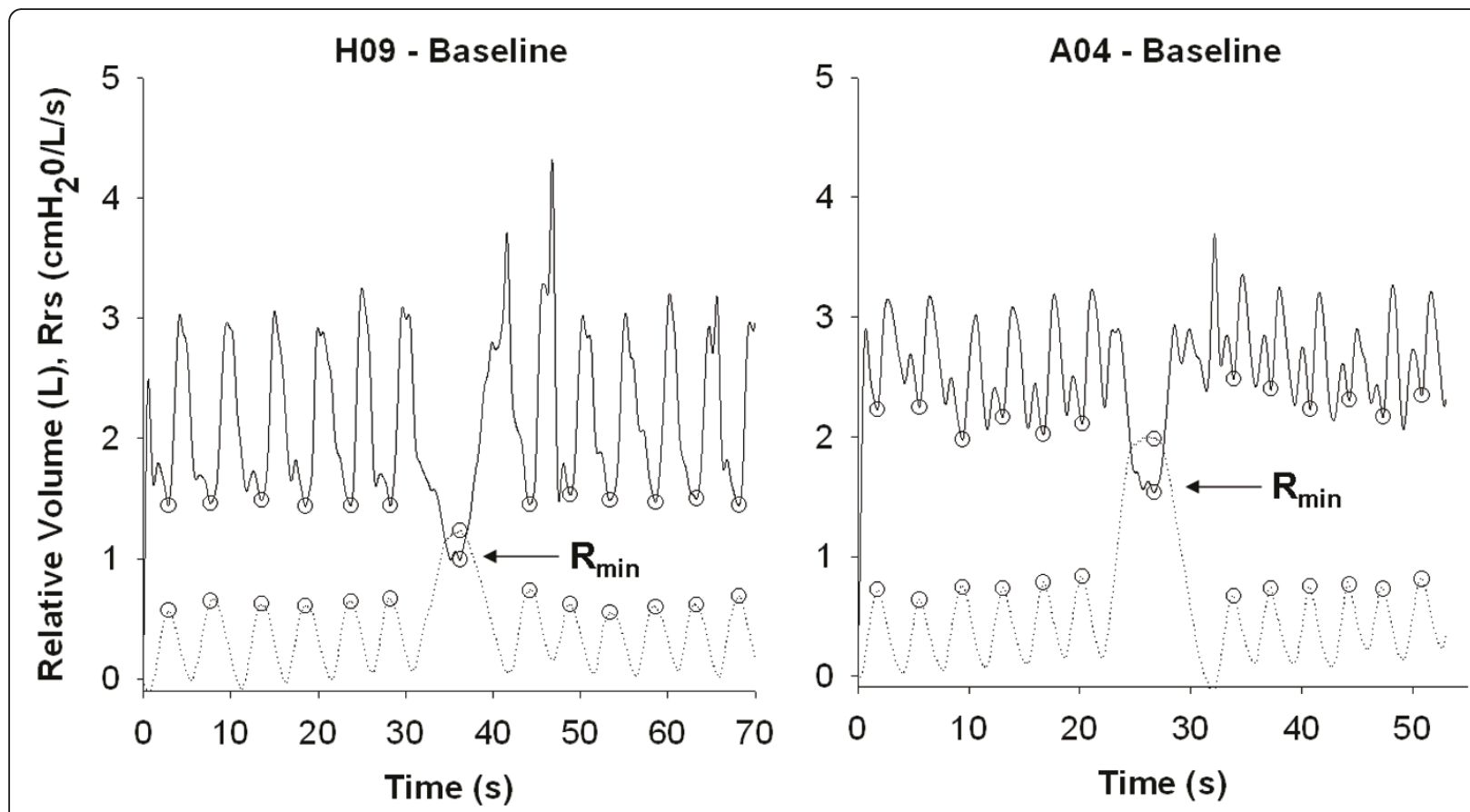

Figure 1 Typical respiratory system resistance tracings for a nonasthmatic and an asthmatic subject. Typical trace of respiratory system resistance $\left(\mathrm{R}_{\mathrm{rs}}\right)$ at $8 \mathrm{~Hz}$ and relative inhaled volume (above functional residual volume) for a nonasthmatic (H09) and asthmatic (A04) subject at baseline. Both participants are female and of similar age, height, and weight. End-inspiration $\mathrm{R}_{\mathrm{rs}}$ values are used in analysis (open circles). The minimum resistance achieved at maximum inspiration is termed $R_{\min }$. The $R_{r s}$ is plotted as a solid line, and the inhaled volume is plotted as a dotted line. 


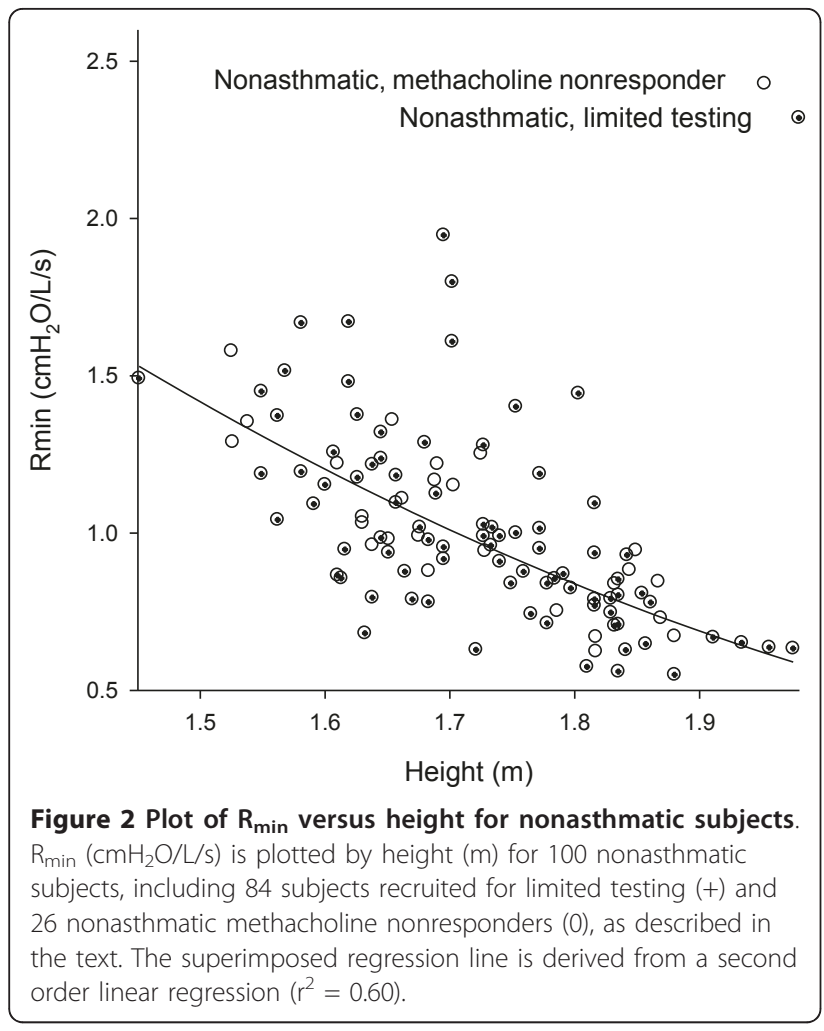

In Figures 4, 5, 6, the methacholine dose-response slope is plotted versus $R_{\min } \%$ predicted (Figure 4), $\mathrm{FEV}_{1}$ $\%$ predicted (Figure 5), and $\mathrm{FEF}_{25-75} \%$ predicted (Figure 6) for nonasthmatic (closed circles) and asthmatic (open triangle) participants. These plots reveal that the $\log _{10}$ dose-response slope was significantly correlated with Rmin \% predicted $(\mathrm{r}=0.50, \mathrm{p}<0.0001), \mathrm{FEV}_{1} \%$ predicted $(\mathrm{r}=-0.40, \mathrm{p}<0.001)$, and $\mathrm{FEF}_{25-75} \%$ predicted $(\mathrm{r}=-0.63, \mathrm{p}<0.00001)$. Defining airway hyperresponsiveness as a methcholine $\mathrm{PC}_{20}<16 \mathrm{mg} / \mathrm{mL}$ (corresponding

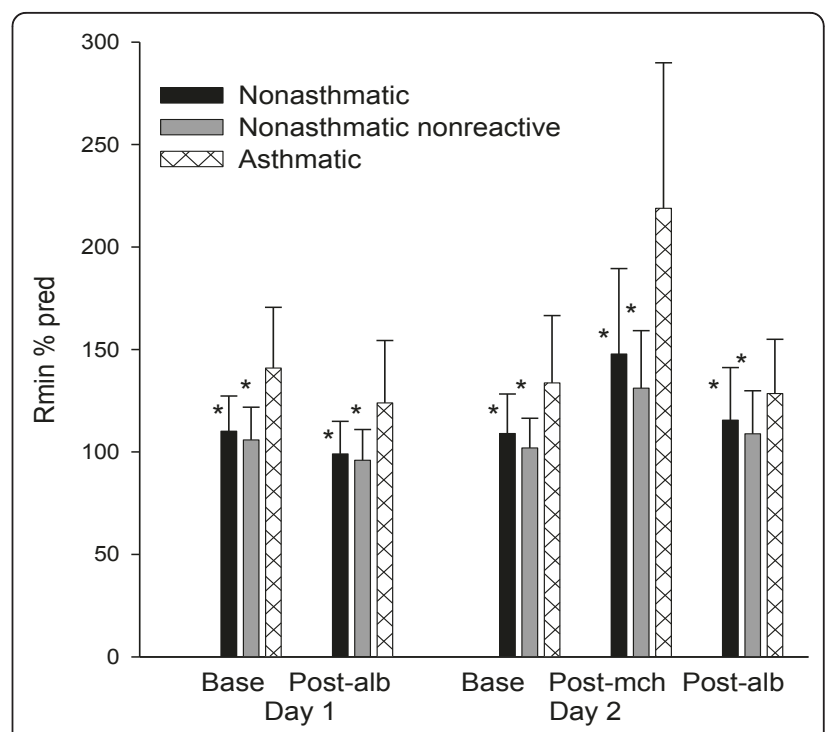

Figure 3 Plot of $R_{\min } \%$ predicted for asthmatic and nonasthmatic subjects. $R_{\text {min }} \%$ predicted for all 34 nonasthmatic (black) and 35 asthmatic (hatched) participants as well as the subgroup of 26 nonasthmatic methacholine nonresponders (gray). *indicates significant difference from asthmatic group in each condition $(p<0.05)$

to a dose-response slope $>1.2), 80 \%$ of the subjects with baseline $\mathrm{R}_{\text {min }}<100 \%$ predicted did not have airway hyperresponsiveness, while $100 \%$ of subjects with $R_{\min }>$ $145 \%$ predicted had hyperresponsiveness, regardless of clinical classification as asthmatic or nonasthmatic.

ROC curves were used to formally compare the ability of these measurements to distinguish hyperresponsive subjects (defined as $\mathrm{PC}_{20}$ less than $16 \mathrm{mg} / \mathrm{ml}$ ) from subjects without hyppresponsiveness and to identify the optimal threshold levels for distinguishing these groups (Figure 7). The thresholds yielding the highest combined

Table 2 Baseline physiologic measurements* in asthmatic and control subjects and in subgroups of these subjects

\begin{tabular}{|c|c|c|c|c|c|c|}
\hline & & $\begin{array}{c}\text { All } \\
\text { subjects }\end{array}$ & & & Subgroups & \\
\hline $\begin{array}{l}\text { Physiologic } \\
\text { measurement }\end{array}$ & $\begin{array}{l}\text { Nonasthmatic } \\
(\mathrm{n}=34)\end{array}$ & $\begin{array}{c}\text { Asthmatic } \\
(\mathrm{n}=35)\end{array}$ & $P$ value & $\begin{array}{c}\text { Nonasthmatic methacholine } \\
\text { nonresponders } \\
(\mathrm{n}=26)\end{array}$ & $\begin{array}{l}\text { Asthmatic methacholine } \\
\text { responders } \\
(\mathrm{n}=31)\end{array}$ & $P$ value \\
\hline $\begin{array}{l}\text { FEV1 } \\
\% \text { predicted }\end{array}$ & $95 \pm 10$ & $88 \pm 11$ & 0.009 & $97 \pm 8$ & $88 \pm 11$ & 0.002 \\
\hline $\begin{array}{l}\text { FEV1/FVC } \\
\% \text { predicted }\end{array}$ & $100 \pm 7$ & $90 \pm 9$ & $\begin{array}{c}< \\
0.0001\end{array}$ & $102 \pm 6$ & $90 \pm 9$ & $\begin{array}{c}< \\
0.0001\end{array}$ \\
\hline $\begin{array}{l}\text { FEF25-75 } \\
\% \text { predicted }\end{array}$ & $93 \pm 20$ & $69 \pm 20$ & $\begin{array}{c}< \\
0.0001\end{array}$ & $99 \pm 18$ & $68 \pm 18$ & $\begin{array}{c}< \\
0.0001\end{array}$ \\
\hline $\begin{array}{l}\mathrm{R}_{\mathrm{rs}} \\
\mathrm{CmH} 20 / \mathrm{L} / \mathrm{s}\end{array}$ & $2.21 \pm 0.48$ & $2.91 \pm 0.99$ & 0.0006 & $2.10 \pm 0.24$ & $2.95 \pm 1.04$ & 0.0005 \\
\hline $\begin{array}{l}R_{\min ,} \\
\mathrm{cmH} 20 / \mathrm{L} / \mathrm{s}\end{array}$ & $1.12 \pm 0.31$ & $1.39 \pm 0.41$ & 0.004 & $1.02 \pm 0.24$ & $1.41 \pm 0.42$ & 0.0001 \\
\hline $\begin{array}{l}\mathrm{R}_{\min ,} \\
\% \text { predicted }\end{array}$ & $109 \pm 19$ & $134 \pm 33$ & 0.0004 & $102 \pm 14$ & $137 \pm 33$ & $\begin{array}{c}< \\
0.0001\end{array}$ \\
\hline
\end{tabular}

* Mean \pm standard deviation. 


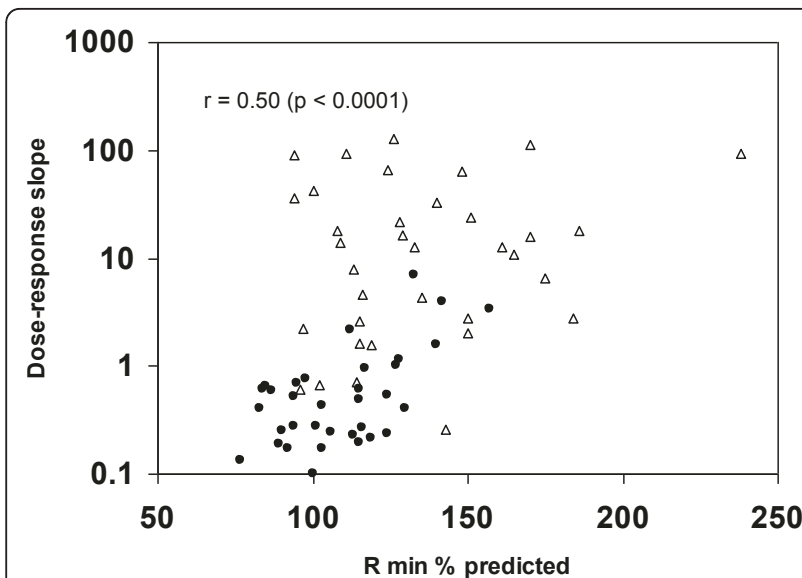

Figure 4 Plot of methacholine dose-response slope versus $\mathbf{R}_{\min }$ percent predicted. Scatter plot of dose-response slope versus baseline $\mathrm{R}_{\min } \%$ predicted for nonasthmatic (closed circles) and asthmatic (open triangle) participants.

sensitivity and specificity were 115 for $\mathrm{R}_{\min } \%$ predicted, 91 for $\mathrm{FEV}_{1} \%$ predicted, and 82 for $\mathrm{FEF}_{25-75} \%$ predicted. The AUC for $\mathrm{R}_{\mathrm{min}}, \mathrm{FEV}_{1}$, and $\mathrm{FEF}_{25-75}$, were $0.85,0.78$, and 0.87 , respectively. The AUC for both the $\mathrm{FEV}_{1} / \mathrm{FVC}$ ratio and $\mathrm{FEF}_{25-75} / \mathrm{FVC}$ ratio (not shown in figure) was 0.81 . The percent increase in $\mathrm{FEV}_{1}$ following albuterol administration on the first day of the protocol was also analyzed and was comparable to $R_{\min } \%$ predicted (AUC $=0.85$ with a threshold of $3.7 \% \mathrm{FEV}_{1}$ increase). ROC curves were also calculated for hyperresponsiveness defined as a $\mathrm{PC}_{20}<25 \mathrm{mg} / \mathrm{ml}$, and in this case the $\mathrm{R}_{\min } \%$ predicted had the highest AUC at 0.87 .

\section{Discussion}

Our goal was to test the hypothesis that the minimal airway resistance achievable during a maximal inspiration

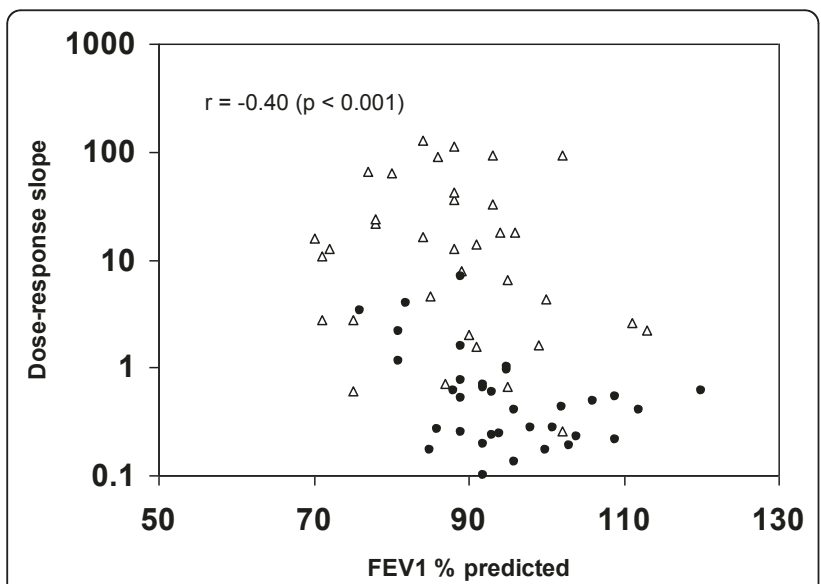

Figure 5 Plot of methacholine dose-response slope versus FEV percent predicted. Scatter plot of dose-response slope versus $\mathrm{FEV}_{1}$ $\%$ predicted for nonasthmatic (closed circles) and asthmatic (open triangle) participants.

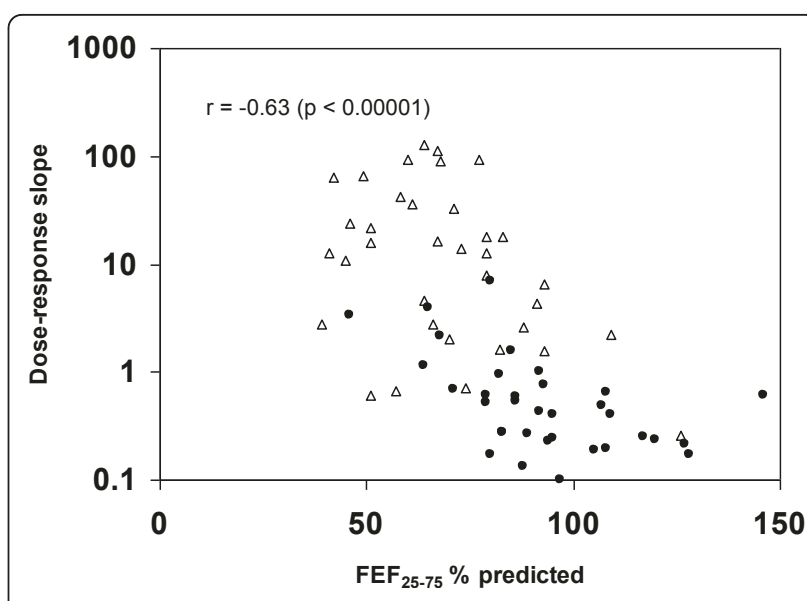

Figure 6 Plot of methacholine dose-response slope versus FEF $_{\text {25-75 }}$ percent predicted. Scatter plot of dose-response slope versus $\mathrm{FEF}_{25-75} \%$ predicted for nonasthmatic (closed circles) and asthmatic (open triangle) participants.

$\left(R_{\min }\right)$ is abnormally elevated in subjects with airway hyperresponsiveness. The breathing maneuver required to measure $R_{\min }$ by the forced oscillation method is less burdensome and less subject to performance-related errors than is spirometry. We observed that the baseline $R_{\min }$, as a percent predicted value based on height, identifies people with airway hyperresponsiveness approximately as well as $\mathrm{FEF}_{25-75}$ and slightly better than $\mathrm{FEV}_{1}$.

Previous reports suggested a decreased ability of asthmatic airways to dilate in response to a deep inspiration, a deficiency that was accentuated after bronchial challenge $[2,11]$ Our measurements in a larger sample of

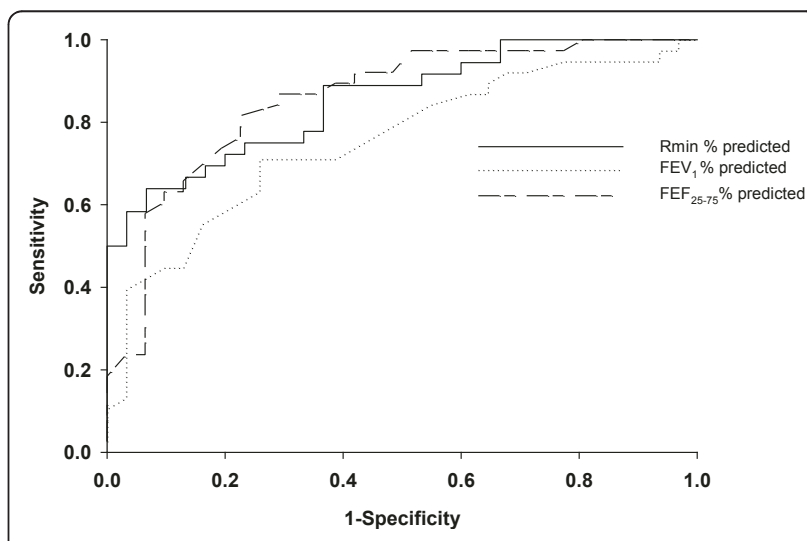

Figure 7 Receiver operator characteristic curves for $R_{\min }, F E V_{1}$, and $\mathrm{FEF}_{25-75}$ as predictors of airway hyperreactvitiy. Receiver operator characteristic (ROC) curves for $R_{\text {min }}, F E V_{1}$, and $F E F_{25-75}$ as predictors of airway hyperresponsiveness $\left(\mathrm{PC}_{20}<16 \mathrm{mg} / \mathrm{ml}\right)$. The thresholds yielding the highest combined sensitivity and specificity were 115,91 , and 82 for $\mathrm{R}_{\min } \%$ predicted, $\mathrm{FEV}_{1} \%$ predicted, and $\mathrm{FEF}_{25-75} \%$ predicted, respectively. The area under the curve (AUC) was $0.85,0.78$, and 0.87 for $\mathrm{R}_{\text {min }} \%$ predicted, $\mathrm{FEV}_{1} \%$ predicted, and $\mathrm{FEF}_{25-75} \%$ predicted, respectively. 
subjects agree with these previous observations. At baseline, $R_{\min }$, an inverse measure of airway caliber, was significantly higher in asthmatics compared to nonasthmatics. Following inhalation of albuterol, subjects with asthma still had higher $R_{\min }$ than nonasthmatics (Figure 3 ). In fact, asthmatic subjects had a higher mean $R_{\min }$ after albuterol than the nonasthmatic methacholine nonresponder group before albuterol (not shown), indicating that in subjects with asthma, albuterol cannot always dilate airways to levels achievable in nonasthmatic airways. This suggests that either albuterol does not relax the airway smooth muscle of asthmatics to the same extent as nonasthmatics or that the airway walls have become stiff or narrowed by other mechanisms. In that our data on response to albuterol suggest that asthmatics have an approximately similar decline in $R_{\text {min }}$ in response albuterol as nonasthmatics (reduction in $R_{\min } \%$ predicted $17 \pm 6.3 \mathrm{SE}$ vs. $11 \pm 2.2 \mathrm{SE}$ for asthmatics and nonasthmatics, respectively; $\mathrm{p}=0.38$ ), this may favor the explanation of residual differences in the airway wall independent of ASM tone. It must be noted that the dose of albuterol administered in our protocol, i.e. $180 \mathrm{ug}$ (two inhalations), is not a maximally bronchodilating dose. When the stiffer asthmatic airway is constricted by methacholine, the inability to dilate with a deep inspiration is exaggerated compared to nonasthmatic participants, the $\mathrm{R}_{\min } \%$ predicted increasing in response to methacholine by $85 \pm 12 \mathrm{SE}$ vs. $38 \pm 5.6 \mathrm{SE}$ $(\mathrm{p}<0.001)$ in asthmatics and nonasthmatics, respectively (Figure 3 ).

There are several factors that influence airway caliber, including airway smooth muscle tone and stiffness, the passive properties of the airway wall (e.g. airway wall thickening), parenchymal tethering and transmural pressure acting to distend the airway. Several of these can be influenced by airway wall remodeling. Direct measurement of airway distensibility in the intact lung (i.e. the relationship between airway caliber and airway distending pressure) is difficult. Recent work by Brown et al. confirms the ability to indirectly assess airway distensibility non-invasively using forced oscillations $[12,13]$. Specifically, distensibility was quantified as the linear slope of respiratory system conductance $\left(1 / R_{\mathrm{rs}}\right)$ and volume between $75 \%$ and $100 \%$ of total lung capacity. This slope was decreased in asthmatics and unaffected by reduction of bronchomotor tone with albuterol. Brown et al. concluded that reduced airway distensibility in asthmatics is consistent with structural changes associated with airway wall remodeling and is not reflective of increased airway smooth muscle tone. This is consistent with the data of our study. Another key determinant of the ability to dilate could be lung elastic recoil pressure; past studies have reported a significant loss of recoil in moderate-to-severe though perhaps not mild asthma[14-16]. We did not measure elastic recoil in our study and can only speculate on its role.

Several limitations of our study must be recognized. The sample size was relatively small $(\mathrm{n}=69$ for the full protocol and $n=84$ for the limited testing to establish predicted values for Rmin), the age range was limited to to 18-29 years, and most subjects were Caucasian race. A larger and more diverse sample would permit better evaluation of the potential relationship of $R_{\min }$ to age and race, as well as subgroup analyses. In addition, the asthmatic subjects had mild to moderate disease, so the full spectrum of asthma was not reflected in our sample, and we were not able to assess the correlation of $R_{\text {min }}$ with clinical status. It is possible that there could be important differences in the physiology of milder versus more severe asthma. Finally, the deep inhalations performed during the dosimeter protocol for methacholine challenge have been reported to result in bronchoprotection and falsely negative challenge results among mild asthmatics, compared to the tidal breathing protocol[17,18]. It would be of interest to have data on the relationship of $R_{\min }$ to airway responsiveness assessed by both protocols.

\section{Conclusions}

Our study reveals that after adjusting for height, $R_{\min }$ differs between asthmatics and nonasthmatics, predicts methacholine responsiveness, increases with administration of methacholine, and decreases with albuterol. Compared to spirometry, this test requires less patient effort and is easier for a technician or clinic staff member to administer with technically acceptable results. In conjunction with symptom history, $\mathrm{R}_{\min }$ could provide a clinically useful tool for assessing asthma control and monitoring the response to treatment. Longitudinal studies are needed to assess the utility of $R_{\min }$ as an indicator of asthma control and response to asthma therapy.

\section{List of abbreviations}

AUC: area under the curve; $\mathrm{PC}_{20}$ :provocative concentration causing a $20 \%$ drop in $\mathrm{FEV}_{1}$; ROC: receiver operator characteristic; $\mathrm{R}_{\text {min }}$ : minimal airway resistance achievable during a deep inspiration; $R_{r s}$ : respiratory system resistance

\section{Acknowledgements}

This work was supported by the National Institutes of Health [GRANT RO1 HL076778].

\section{Author details}

'Department of Biomedical Engineering, 44 Cummington St., Boston University, Boston, MA 02215, USA. ${ }^{2}$ Pulmonary Center, Boston University School of Medicine, 72 E. Concord St., Boston, MA 02118, USA.

\section{Authors' contributions}

NTM contributed to study design, acquisition of data, analysis and interpretation of data, and drafting and revising the manuscript. JK contributed to study design, acquisition of data, analysis and interpretation of data, and drafting and revising the manuscript. ASL contributed to 
acquisition of data, analysis and interpretation of data, and drafting and revising the manuscript. SNS contributed to study design, acquisition of data, analysis and interpretation of data, and drafting and revising the manuscript. GTO contributed to study design, acquisition of data, analysis and interpretation of data, and drafting and revising the manuscript. KRL contributed to study design, acquisition of data, analysis and interpretation of data, and drafting and revising the manuscript. All authors read and approved the final manuscript.

\section{Competing interests}

The authors declare that they have no competing interests.

Received: 7 September 2010 Accepted: 15 July 2011

Published: 15 July 2011

\section{References}

1. Mazzarella G, Stendardi L, Grazzini M, Scano G: Mechanisms involved in airway obstruction: the role of smooth muscle. Allergy 2000, 55(Suppl 61):46-48.

2. Jensen A, Atileh $H$, Suki B, Ingenito EP, Lutchen KR: Selected contribution: airway caliber in healthy and asthmatic subjects: effects of bronchial challenge and deep inspirations. J Appl Physiol 2001, 91(1):506-515, discussion 504-505.

3. Salome CM, Thorpe CW, Diba C, Brown NJ, Berend N, King GG: Airway renarrowing following deep inspiration in asthmatic and nonasthmatic subjects. Eur Respir J 2003, 22(1):62-68.

4. Black LD, Dellaca $R$, Jung $K$, Atileh $H$, Israel $E$, Ingenito EP, Lutchen KR: Tracking variations in airway caliber by using total respiratory vs. airway resistance in healthy and asthmatic subjects. J Appl Physiol 2003, 95(2):511-518.

5. Crapo RO, Casaburi R, Coates AL, Enright PL, Hankinson JL, Irvin CG, MacIntyre NR, McKay RT, Wanger JS, Anderson SD, et al: Guidelines for methacholine and exercise challenge testing-1999. This official statement of the American Thoracic Society was adopted by the ATS Board of Directors, July 1999. Am J Respir Crit Care Med 2000, 161(1):309-329.

6. Todd DC, Davis BE, Smycniuk AJ, Cockcroft DW: Importance of dosimeter calibration method on nebulizer output. Ann Allergy Asthma Immunol 2005, 94(1):45-47.

7. Crapo RO, Morris AH, Gardner RM: Reference spirometric values using techniques and equipment that meet ATS recommendations. Am Rev Respir Dis 1981, 123(6):659-664.

8. Miller MR, Hankinson J, Brusasco V, Burgos F, Casaburi R, Coates A, Crapo R, Enright $P$, van der Grinten CP, Gustafsson P, et al: Standardisation of spirometry. Eur Respir J 2005, 26(2):319-338.

9. O'Connor G, Sparrow D, Taylor D, Segal M, Weiss S: Analysis of doseresponse curves to methacholine. An approach suitable for population studies. The American review of respiratory disease 1987, 136(6):1412-1417.

10. Hoaglin DC, Mosteller F, Tukey JW: Understanding robust and exploratory data analysis.Edited by: David C Hoaglin, Frederick Mosteller, John W Tukey. New York Wiley; 1983:.

11. Black LD, Henderson AC, Atileh $H$, Israel E, Ingenito EP, Lutchen KR: Relating maximum airway dilation and subsequent reconstriction to reactivity in human lungs. J Appl Physiol 2004, 96(5):1808-1814.

12. Brown NJ, Salome CM, Berend N, Thorpe CW, King GG: Airway distensibility in adults with asthma and healthy adults, measured by forced oscillation technique. Am J Respir Crit Care Med 2007, 176(2):129-137.

13. Brown NJ, Thorpe CW, Thompson B, Berend N, Downie S, Verbanck S, Salome CM, King GG: A comparison of two methods for measuring airway distensibility: nitrogen washout and the forced oscillation technique. Physiol Meas 2004, 25(4):1067-1075.

14. Gelb AF, Zamel N: Unsuspected pseudophysiologic emphysema in chronic persistent asthma. American journal of respiratory and critical care medicine 2000, 162(5):1778-1782.

15. Gelb AF, Licuanan J, Shinar CM, Zamel N: Unsuspected loss of lung elastic recoil in chronic persistent asthma. Chest 2002, 121(3):715-721.

16. Sciurba FC: Physiologic similarities and differences between COPD and asthma. Chest 2004, 126(2 Suppl):117S-124S, discussion 159S-161S.
17. Allen ND, Davis BE, Hurst TS, Cockcroft DW: Difference between dosimeter and tidal breathing methacholine challenge: contributions of dose and deep inspiration bronchoprotection. Chest 2005, 128(6):4018-4023.

18. Cockcroft DW, Davis BE: The bronchoprotective effect of inhaling methacholine by using total lung capacity inspirations has a marked influence on the interpretation of the test result. The Journal of allergy and clinical immunology 2006, 117(6):1244-1248.

doi:10.1186/1465-9921-12-96

Cite this article as: Mendonça et al:: Airway resistance at maximum inhalation as a marker of asthma and airway hyperresponsiveness. Respiratory Research 2011 12:96.

\section{Submit your next manuscript to BioMed Central and take full advantage of:}

- Convenient online submission

- Thorough peer review

- No space constraints or color figure charges

- Immediate publication on acceptance

- Inclusion in PubMed, CAS, Scopus and Google Scholar

- Research which is freely available for redistribution

Submit your manuscript at www.biomedcentral.com/submit
C Biomed Central 